trouble to express an opinion, it has to be assumed that it has no opinion. Nor will it do to say that these groups of concerned people do not understand the highly technical issues; it is the duty of the authority (the Central Electricity Generating Board, or the Ministry of Transport, or whoever proposes the project under discussion) to set out the issues in a way which can be understood by laymen.

We have an opportunity for an experiment in participation in England. The proposal to mine coal in the Vale of Belvoir is going to arouse savage opposition. The issues are highly complex. Would it be possible for the adjoining universities (Nottingham, Leicester, and Loughborough) to arrange extra-mural courses about the issue, conducted by experts in geology, energy technology, and economics who would not be regarded as in the pay of the Coal Board? And - but perhaps this is going too far - would it be possible for witnesses holding a class certificate from one of these extra-mural courses to be given preference in the public enquiry which will doubtless be held? A procedure like this might not lead to a wiser decision (though it might do that too), but it would be likely to increase confidence and sympathy for the decision. And in a pluralistic democracy the process is as important as the end product.

Lord Ashby is Chancellor of Queen's University, Belfast, and $a$ Fellow of Clare College, Cambridge, UK.

\section{Bumblebee economics}

Bumblebee Economics. By Bernd Heinrich. Pp. 159. (Harvard University Press: Cambridge, Massachusetts, and London, UK, 1979.) \$21.90; £11.40.

FIVE books dealing entirely with bumblebees have been published previously, in 1912, 1934, 1959, 1975 and 1978 , and three other books, published in 1970,1971 and 1974, have substantial parts devoted to bumblebees. The justification for producing another book on bumblebees would need to rest on significant advances in the subject or on a new approach. Certainly Bernd Heinrich gives us a refreshingly different and topical approach.

The central theme running through his book is that of energy economics, and most of the activities of individual bumblebees and of bumblebee colonies are examined in the light of profit and loss of energy resources. Bumblebees are particularly suited for such an examination. They live in temperate climates and often need to survive low temperatures. To ensure that the susceptible brood does not become chilled, the adults produce heat by metabolic activity and surround the comb with insulating material to retain it.

However, the ultimate object of a bumblebee colony is to convert the nectar and pollen collected by its foragers into sexually developed adults that mate and reproduce. Calculating the energy balances and the effects of likely changes in the collection, flow and expenditure of resources is shown to be fascinating but complex. For example, bumblebees are well known for their ability to fly and forage at relatively low temperatures and in adverse weather conditions, but the success of the currently in vogue phrase, 'foraging strategy', will depend on the energy they need to expend before flight is possible, the amount of fuel (nectar) they consume to reach the foraging area, whether sufficient nectar is being produced, and whether it contains a sufficient concentration of sugars; both these latter factors are also controlled by environmental temperature and relative humidity. It is easy to envisage circumstances in which a forager would use more sugar than it actually collected. Furthermore foraging in poor weather conditions can be hazardous as well as arduous, and so diminish longevity and the energy resources of the bee's colony. Even in favoured foraging conditions several trips are needed to produce sufficient nectar and pollen to rear one worker bee, and Heinrich calculates that to rear one queen requires the nectar and pollen loads collected by a worker during two days of continuous foraging.

We are still lacking information on the precise mechanisms that instigate queen production. Increase in colony size and decrease in brood/worker ratio release a greater proportion of bees for foraging so the collection of sufficient forage for queen production should become possible. However, larger colonies need larger foraging areas to support them, so

\section{Fluid compositions in the Earth's crust}

Fluids in the Earth's Crust: Their Significance in Metamorphic, Tectonic and Chemical Transport Processes. By W. S. Fyfe, N. J. Price and A. B. Thompson. Pp. 372. (Elsevier Scientific: Amsterdam and New York, 1978.) \$49.75; Dfl. 125.

THE authors in the Preface of this book say that it is an attempt to link metamorphic processes and rock mechanics, to provide a text unifying the fields of metamorphic petrology and structural geology. In one sense, they have individual foragers will need to forage further afield with dimin ished efficiency. As a colony becomes larger so does the average size of the worker so the larger forager and its greater load bearing capacity may more than com pensate for an increased foraging area!

Heinrich also discusses how bumblebees interrelate with other animals and plants in their environment, and stresses especially the effect of bumblebee pollination on the production of fruits and seeds, that in turn provide the diet of much wildlife. In contrast to most insects that forage on plants, visits by bees actually increase the likelihood that the plants will rep roduce, and so provide additional forage and energy requirements for succeeding generations of bees.

This book is written for the nonspecialist; although easy to read the st yle is sometimes too colloquial for my taste. I see no point in calling empty cocoons "silken cradles" or to liken the adult bee to a "miniature helicopter" or "a small, furr y, orange, black and yellow object". But few can avoid the temptation to try to wax poetic about the bumblebee.

Quite rightly, Heinrich pays particular attention to his own research and its implications. Although at times the reader is too frequently reminded to regard the bumblebee in terms of energy balance and allocation of resources, the central theme proves a useful one and serves the double purpose of binding the work into a coherent whole and allowing the author to return easily to his main line of thought after frequent digressions. There are two short appendices, on how to rear bumblebees and on the bumblebee species of North America, and a list of selected references.

This is a good book, packed with information. I recommend it as essential reading to those interested in social insects and hope it will find the wider readership it deserves.

John B. Free

John B. Free is at Rothamsted Experimental Station, Harpenden, UK.

admirably accomplished this task. The success of the book is that from the varied viewpoints and experiences of the authors, it is a synthesis of a portion of these complex and diverse fields. The general theme is the link between fluid compositions in the crust as controlled by equilibrium metamorphic mineral assemblages and kinetics, mass transport during metamorphic processes, and tectonics. The role of fluids in crustal processes is strongly emphasised. However, as the authors state, this text is not traditional or classic or allencompassing.

Chapter 1 sets the stage, providing the focus for the link between fluid motion, geochemical and tectonic processes. It is a 